\begin{abstract}
The primary argument of this paper is, namely, that the International Accounting Standards Board (IASB), is in need of an enforcement mechanism. In drawing attention to this argument, the paper not only proposes considerations which are to be taken into account if such a mechanism is to be implemented, but also considers areas in which the regulation of accounting standards, and auditing standards in particular, have contributed to the recent global financial crisis. The impact of such standards on pro cyclicality ${ }^{l}$, the level of success achieved by the IASB and other international standard setters such as the Basel Committee on Banking Supervision, relates to how effectively the accounting and audit standard setting is implemented.

As well as identifying the importance of convergence in contributing towards high quality audits and the consistent application of auditing and accounting standards, this paper also acknowledges the difficulties and challenges encountered in attempting to achieve a convergent framework. Furthermore, through a discussion of recommendations aimed at consolidating transparency and accounting, as proposed by the G20, ways in which accounting standards, and consequently the IASB, could contribute further to the improvement of transparency and accountability of the framework for fair value measurements and evaluation, are considered.

The absence of enforcement mechanisms, the fact that enforcement actions are carried out at national level in various EU member states, present sources of obstacles to attempts to realise the proposals put forward by the G20. This paper not only attempts to address such factors, but also to suggest ways in which the IASB, to an extent, could realise its goals. Through a consideration of two enforcement regimes in Europe, namely, Germany and the UK, two related standards which govern enforcement in Europe, principles on which harmonisation of the institutional oversight systems in Europe may be achieved, and the vital contribution made by CESR and EFRAG (the European Financial Reporting Advisory Group), this paper will consider how enforcement could be implemented by the IASB at European level.
\end{abstract}

1 This is the tendency for periods of financial and economic downturns or booms to be further exacerbated. Certain economic or financial policies could also be pro cyclical. For example, Basel II's pro cyclical effects have been criticised. 


\section{The Role of the IASB and Auditing Standards in the Aftermath of the 2008/2009² Financial Crisis.}

\section{Introduction}

Accounting and the regulation of auditing standards in particular, have contributed to the current global crisis. $^{3}$ Other causes of the financial crisis are attributed to the following factors: ${ }^{4}$ Macroeconomic causes (for example "ample liquidity", low interest rates and excessively loose monetary policy), risk management by firms, supervisors and regulators, credit rating agencies (failures in the ratings procedures of such agencies and conflicts of interests), corporate governance ("weak shareholders, management of firms and remuneration schemes" which generate inappropriate incentives), regulatory and supervisory failures (inclusive of pro cyclical issues, mark to market accounting, lack of regulation of derivatives markets) and lack of global coordination between institutions such as the IMF, FSF and G20. The Report of the High Level Group on Financial Supervision in the EU considers means whereby the organisation of supervision of financial institutions, the consolidation of European cooperation on financial stability oversight, early warning and crisis mechanisms, can be undertaken. ${ }^{5}$ Furthermore, it recommends ways whereby EU supervisors could collaborate on a global basis. ${ }^{6}$

Despite these efforts, the Report does not accord as much level of attention as one would have wished, to important issues such as maturity mismatches ${ }^{7}$ and pro cyclicality ${ }^{8}$. These issues are acknowledged minimally in the Report, and the High Level Group's recommendations in relation to such issues are considered to be too passive. ${ }^{9}$ An international standard setter such as the IASB with enforcement mechanisms would be able to add the "bite" required in activating and enforcing standards related to pro cyclicality and maturity mismatches. The Basel Committee for Banking Supervision is another international standard setter who faces problems attributed to lack of effective enforcement mechanisms. Proposals made by the High Level Group to the Basel Committee are therefore considered passive where the Basel

\footnotetext{
2 It is acknowledged that the recent Financial Crisis broke out in 2007. Hence reference will be made to 2007 in relation to incidences prior to the Financial Crisis.

3 See 'Report of the High Level Group on Financial Supervision', February 2009

$<$ http://www.iasplus.com/restruct/euro2009.htm>and particularly, the 'Brief Summary of the De Larosiere Report'<http://ec.europa.eu/commission_barroso/president/pdf/statement_20090225.pdf>at 3

$4 \quad$ See 'Brief Summary of the De Larosiere Report' at 2

5 See 'EU Supervision Report Criticises IASB' < http://www.iasplus.com/restruct/euro2009.htm>

$6 \quad$ ibid

$7 \quad$ A situation which arises where disparity exists between the duration of maturity of assets and liabilities. It could occur where the duration of maturity for liabilities exceeds that of assets (short term) and also where the duration of term for assets exceeds that of liabilities (medium and long term). For example, where an undertaking possesses more short term liabilities than short term assets or more assets than liabilities for medium and long term obligations. The disparity between the periods of maturity for assets and liabilities could determine the state of the company's liquidity.

$8 \quad$ supra note 1

$9 \quad$ See page 43 of the Report

<http://ec.europa.eu/internal_market/finances/docs/de_larosiere_report_en.pdf>The High Level Group proposed a "fundamental review of the Basel II rules" with the Basel Committee of Banking Supervisors being called upon to make amendments to such rules for the purpose of increasing minimum capital requirements in a gradual manner, reducing pro cyclicality through the facilitation of dynamic provisioning or capital buffers, introducing more stringent requirements for off balance sheet items, introducing stricter rules for the management of liquidity, and consolidating rules for banks' internal control and risk management ( See Report of the High Level Group on Financial Supervision, February 2009)
} 
committee continues to lack effective enforcement mechanisms required to activate and enforce its standards.

This paper commences with a discussion which considers how audit standards could contribute towards providing high quality audits. Some factors which are crucial to the achievement of this aim, namely, global convergence, and the international setting system, are then considered. If the convergence of international financial reporting standards could be achieved, such standards, when applied on a global basis, would facilitate competitiveness. Convergence would also facilitate consistency in the application of auditing standards, which in turn, would facilitate comparability. Within this context, the difficulties which exist in achieving global convergence, given the fact that difficulties arise in consistently applying accounting standards across national boundaries, will be addressed.

This will be followed by a discussion on the historical developments of international standard setters such as the IASB, which have been assigned with the task of issuing and developing a unified set of global accounting standards. In complementing this discussion, the EC Regulation No 1606/2002 on the application of international accounting standards, will be introduced.

A consideration of the aims intended to be realised under the Regulation will then set the scene for a discussion of problems which had been identified prior to the 2007/2009 Financial Crisis and the progress which has been made by the IASB so far, having consideration to the aims stated under the EC Regulation No 1606/2002, problems identified before the 2007/2009 Financial Crisis, and problems which still persist. The accomplishment of such an evaluation will be facilitated through a consideration of the lessons and issues learned from the crisis and steps taken by the IASB to address such issues. A consideration of obstacles which could serve as impediments to the IASB's efforts to address issues arising from the recent financial crisis, will then be considered.

Greatest attention will be dedicated to enforcement - given the fact that the IASB does not currently possess an enforcement mechanism. A consideration of two enforcement regimes operating in Europe and a consideration of the two related standards which govern enforcement in Europe, namely, CESR Standard No 1 (Enforcement of Standards on Financial Information in Europe) and CESR Standard No 2 (Coordination of Enforcement Activities) should help in drawing a proposal on how enforcement could be implemented at European level.

This would then be followed by a concluding section which includes, amongst other proposals, recommendations made by the Federation des Experts Comptables Europeens (FEE) on how the IASB's principle based approach to the standard setting process should be carried out.

\section{The Importance of Timeliness, Accuracy and Consistency in the Financial Standard Setting Process.}

"Auditing standards are crucial to providing high quality audits". ${ }^{10}$ However, in order for such standards to achieve such desired aims, they should be timely, consistent and accurate. International Financial Reporting Standards (IFRSs), to a greater extent, have the potential to facilitate the realisation of such aims. Generally, IFRSs should promote increased

$10 \quad$ See 'A First EU Response to Enron Related Policy Issues'

<http://ec.europa.eu/internal_market/company/docs/enron/ecofin_2004_04_enron_en.pdf > at 3 
comparability - thereby resulting in "reduced information costs and information risk to investors" if these are implemented with consistency. ${ }^{11}$ Accuracy has assumed greater importance over the years in terms of uncertainties in provisioning and fair value measurements.

"The international standard setting system", it is contended, "is the best way forward." issue relating to whether accounting rules instigated or did not instigate the Financial Crisis, and whether they merely served to exacerbate the Crisis has also been raised. ${ }^{13}$ Furthermore, the need for a consideration of an adjustment of accounting rules for purposes aimed at bolstering the financial system, has also been highlighted. ${ }^{14}$

International accounting standards which can be used globally would facilitate competitiveness within community capital markets when the convergence of such standards was achieved. ${ }^{15}$

\section{A. Reasons Attributed to Inconsistent Application of Auditing Standards}

Certain elements of financial reporting require some degree of judgement, which being subjective, contribute further to the audit expectations gap ${ }^{16}$. Elements such as accounting accruals (provisioning, fair value measurements), the absence of a single set of rules which serves as guidance for fair value measurements contribute to the difficulty of ensuring consistent application, and hence comparability.

Ball expresses his sceptism for a common global set of accounting rules owing to difficulties which arise in consistently applying accounting standards across national boundaries ${ }^{17}$ and refers to certain factors such as accounting accruals - which require some degree of subjective element and fair value measurements, for example, International Accounting Standards 36 and 38, whose fair value measurements vary over time. The possibility that all managers and auditors would painstakingly investigate firms' portfolios to identify "economically impaired assets" with the same level of diligence in all countries adopting IFRSs, in his opinion, is highly improbable. ${ }^{18} \mathrm{He}$ specifically contends that "the case for imposing accounting uniformity by fiat is far from clear."19

\section{B. The IASB and Regulation (EC) No 1606/2002}

11 R. Ball, 'International Financial reporting Standards (IFRSs): Pros and Cons For Investors' 2006 Accounting and Business Research International Accounting Policy Forum at 11

12 See 'International Financial Reporting Standards in Europe: Commissioner McCreevy Comments on Accounting and Financial Crisis' Seeks Loss Provisioning Reforms"< http://www.iasplus.com/restruct/euro2009.htm> and Speech by C McCreevy, "Some Aspects of Economic and Financial Crisis"http://www.iasplus.com/europe/0906mccreevy.pdf

13 ibid

14 'International Financial Reporting Standards in Europe: McCreevy Seeks Loss Provisioning Reforms" $<$ http://www.iasplus.com/restruct/euro2009.htm>

See Regulation (EC) No 1606/2002 on the application of international accounting standards at Recital $\operatorname{no}_{16} 5$

16 The difference between what users of financial statements, the general public perceive an audit to be and what the audit profession claim is expected of them in conducting an audit.

17 R. Ball, 'International Financial reporting Standards (IFRSs): Pros and Cons For Investors' 2006

Accounting and Business Research International Accounting Policy Forum at 6 and 17

$18 \quad$ ibid at 17

19 ibid 
The International Accounting Standards Committee (IASC), a body assigned with the task of issuing International Accounting Standards, continually strives towards the development of a unified set of global accounting standards. ${ }^{20}$ On $1^{\text {st }}$ April 2001, following its restructuring, the newly constituted IASC was renamed the IASB whilst International Accounting Standards (IASs) were renamed International Financial Reporting Standards. ${ }^{21}$ However, the IASB still acknowledges previously existing standards (IASs) which had been issued by the IASC. The European Financial Reporting Advisory Group (EFRAG), a private sector body which was established in 2001 by prominent European organisations within the European capital markets $^{22}$, was created for purposes directed at assisting the European Commission with the "endorsement" of International Financial Reporting Standards (IFRSs), through its provision of advice related to the quality of such standards. ${ }^{23}$

The formalisation of EFRAG's role occurred in March 2006 and the Working Arrangement which constitutes the basis of the formalisation states that "EFRAG will provide advice to the Commission on all issues relating to the application of IFRSs in the EU." ${ }^{24}$ Responsibilities for oversight of EFRAG's work is undertaken by a supervisory board and furthermore, it carries out its activities through a technical group (TEG) whose chairman is a full time auditor. ${ }^{25}$

The inadequacies ${ }^{26}$ of the reporting requirements of the following directives, namely: Council Directive 78/660/EEC of 25 July $1978^{27}$, Council Directive 83/349/EEC of 13 June $1983^{28}$, the Council Directive 86/635/EEC of 8 December $1986^{29}$ and Council Directive 91/674/EEC of 19 December $1991,{ }^{30}$ were identified as reasons for the need to "supplement the legal framework applicable to publicly traded companies.",31

\section{Aims of the Regulation}

The 2002 Regulation 32 aims to contribute to "the efficient and cost effective functioning of the capital market". ${ }^{33}$ Features which constitute important components in the functioning of the capital market, are namely, the protection of investors and the maintenance of confidence in the financial markets. ${ }^{34}$ The Regulation also aims to "reinforce the freedom of movement of capital in the internal market" and facilitate competition (at the same level )between community companies. As was previously discussed, International Financial Reporting

\footnotetext{
20 See Regulation (EC) No 1606/2002 on the application of international accounting standards at Recital no 7 
Standards are capable of facilitating timely, accurate and consistent application of auditing standards - however, owing to difficulties in objectively interpreting certain elements of financial reporting, the IASB faces a difficult task in its efforts to ensure the consistency of application of audit standards across national boundaries. The IASB is currently undertaking measures aimed at introducing greater consistency and reducing complexity in the interpretation of certain financial reporting standards. ${ }^{35}$

EFRAG accomplishes its task as a technical committee in accordance with Regulation (EC) No 1606/2002. ${ }^{36}$ Through the Accounting Regulatory Committee (ARC) in which EFRAG serves as an official adviser, the European Commission also benefits from the advice of member states. ${ }^{37}$

\section{Problems Identified with Accounting Standards Prior to the 2007/2009 Financial Crisis}

- International accounting and auditing standards on their own, do not prescribe rules which provide guidance on how regulation should be effectively carried out. ${ }^{38}$ Since no direction is given in relation to the means whereby international standards could be translated into national legislation, there is a need for the IASB to stipulate situations where the use of "full" IAS/IFRSs will be applicable, and to also establish standards which would fulfil the demands of users of financial statements of other enterprises with particular reference, to small and medium sized businesses (SMEs). ${ }^{39}$ As was indicated by the results of the ROSC, the focus on "legal requirements and competence" on their own, is not sufficient - since enforcement also plays a crucial role. $^{40}$

- The inappropriateness of the scope of application of international standards was also an area where a flaw was highlighted.

- It is contended that international standards do not always focus on the protection of the public's interest. ${ }^{41}$ Further, there is a widely shared consensus amongst stakeholders that fraud detection should be recognised as a responsibility for statutory auditors hence the widening of the scope of audits, beyond that which is currently prescribed by the International Standards on Auditing and Fraud, to include the detection of fraud as an "affirmative" obligation. ${ }^{42}$

35 See 'IASB/IASC Foundation Response to April 2009 G20 Recommendations' < http://www.iasb.org/NR/rdonlyres/3E1B44D3-DE0C-4684-905F51CD0C70BDB5/0/UpdatedAprilG20Matrix21April.pdf>

Under this Regulation, which mandates the application of IFRSs by all European listed companies, in their consolidated financial statements, as from 2005, the European Commission is to obtain advice from a technical committee before it endorses standards. See http://www.efrag.org/content/default.asp?id=4103 $37 \quad$ ibid

38 "Implementation of International Accounting and Auditing Standards: lessons learned from the World Bank's Accounting and Auditing ROSC ( Report on the Observance of Standards and Codes) Program, 2004"

at 5 of 26

39 ibid

$40 \quad$ ibid

$41 \quad$ ibid at 16 of 26

42 ibid 
Over the years, and since 2005 in particular, significant developments aimed at introducing generally accepted standards, both in the EU and globally, have taken place. As of 2004, it could be argued that no generally accepted standards existed in the EU. ${ }^{43}$ Furthermore, the oversight and supervisory framework for the audit profession in the EU was lacking in several aspects, namely, the level of inconsistencies and discrepancies which existed in the application of IFRSs within national members states of the EU, and amongst countries globally, and other flaws which have been discussed in the above mentioned paragraphs. These inadequacies and flaws were addressed by the IASB in the aftermath of the 2008/2009 Financial Crisis.

During the "Conference on Financial Reporting in a Changing World", several areas where financial reporting required greater attention, as revealed by the 2007/2009 Financial Crisis, were brought to light. These areas include the difficulties presented by IAS $39^{44}$ - which in part, are attributed to the number of classifications of assets and accounting treatment which it contains. ${ }^{45}$ Furthermore, its role in impeding transparency and in the deterrence of sales, hence facilitating the avoidance of loss recognition, was also highlighted. ${ }^{46}$ Other areas of persisting problems include those attributed to "technical weaknesses" of present IFRS rules ${ }^{47}$ - with particular respect to off balance sheet entities, de-recognition, and impairment. ${ }^{48}$

Lessons learned from the Crisis, as stated in the Conference are as follows: ${ }^{49}$

- The inter connective and mobile nature inherent in world capital markets

- The inability of operators to comprehend the magnitude and impact of the risks which they had undertaken and the need for greater transparency in financial reporting

- The number of options presented by current rules, which not only added to its complexity, but also reduced comparability.

The IASB has taken steps to amend the IAS 39 standard which deals with financial instruments. These, amongst other responses of the $\mathrm{IASB}^{50}$, respond to the G20's request for a simplification of accounting rules and also the improvement of standards for purposes of

$43 \quad$ See 'A First EU Response to Enron Related Policy Issues' http://ec.europa.eu/internal_market/company/docs/enron/ecofin_2004_04_enron_en.pdf at 3

This Standard is aimed at 'establishing principles for recognising and measuring financial assets, financial liabilities and some contracts to buy or sell non-financial items'. See IAS 39 Financial Instruments, Recognition and Measurement <http://www.iasb.org/NR/rdonlyres/1D9CBD62-F0A8-4401-A90D483C63800CAA/0/IAS39.pdf>

45 P. Ebling, Conference on Financial Reporting in a Changing World, 7-8 May 2009 at 2 of 5

46 ibid

47 IFRS requirements are not only considered to be complex for users and those who prepare such rules, but are considered not to be fully inconsistent with other IFRS requirements. These issues are currently being addressed by the IASB and it has published two exposure drafts - with final drafts being expected by mid 2010 .

$48 \quad$ See P. Ebling, 'Overview of Accounting Issues Raised by the Crisis' Conference on Financial Reporting in a Changing World, at 2 of 5

$49 \quad$ See ibid at 1

$50 \quad$ Other responses aimed strengthening transparency and accountability include the permission given by the IASB for the reclassification of particular financial instruments under certain conditions, and the preparation of an exposure draft of an IFRS which deals with fair value measurement for purposes of providing a unique source where guidance could be given for all fair value measurements. See 'IASB/IASC Foundation Response to April 2009 G20 Recommendations'.< http://www.iasb.org/NR/rdonlyres/3E1B44D3-DE0C-4684-905F51CD0C70BDB5/0/UpdatedAprilG20Matrix21April.pdf> 
valuing financial instruments according to their liquidity. ${ }^{51}$ These steps also respond to the ECOFIN Ministers' request for a restoration of the "level playing field on the key issue of impairments of AFS debt securities" and other areas highlighted by the European Commission in October 2008. ${ }^{52}$ In March 2008, an agreement was reached by the IASB and FASB to replace IAS 39 with a standard which is accepted globally. ${ }^{53}$

The model on which financial reporting is currently founded has also been criticised as being "sub-optimal" and this is attributed to the fact that it focuses entirely on financial information. ${ }^{54}$ According to Phillips, financial reporting is not solely based on accounting and should generate a corporate reporting system which would require a unique global framework. ${ }^{55}$ In his opinion, vital information which relate to the environment in which the business operates, strategies, and a model for the business which associates principal risks and how they are managed, are lacking in the present model. ${ }^{56}$

Within the context of such "unique global framework", the role and contribution attributed to a collaboration between international standard setters such as the IASB, the Basel Committee for Banking Supervision and the US Financial Accounting Standards Board, cannot be overemphasised. The following section considers progress which has been made in relation to greater collaboration between the IASB and the US Financial Accounting Standards Board (FASB) - particularly in response to the Financial Crisis.

\section{E. The Financial Crisis Advisory Group (FCAG)}

The IASB has been working closely with the FASB in response to efforts initiated by the IASB earlier in 2009 and in an aim to achieve targeted recommended improvements with particular off balance sheet items. "The FCAG was established by the International Accounting Standards Board (IASB) and the US Financial Accounting Standards Board (FASB) to advise the two boards about standard-setting implications of the global financial crisis and potential changes to the global regulatory environment. It consists of 18 senior leaders with broad international experience with financial markets, joined by official observers representing key global banking, insurance, and securities regulators". 58

51 See "Stakeholders' Meeting on IASB's IAS 39 revision - Phase I. Exposure Draft" < http://ec.europa.eu/internal_market/accounting/docs/ias/2009-0722 IAS 39 Stakeholders summary en.pdf

$52 \quad$ ibid

53 See 'IASB/IASC Foundation Response to April 2009 G20 Recommendations' .< http://www.iasb.org/NR/rdonlyres/3E1B44D3-DE0C-4684-905F51CD0C70BDB5/0/UpdatedAprilG20Matrix21April.pdf>

$54 \quad$ See comments by D Phillips; „The Future Direction of Accounting: The Future of Corporate Reporting“,Conference on Financial Reporting in a Changing World, at 4 of 5

55 ibid

$56 \quad$ ibid

57 Items which are not reflected on the balance sheet. To an extent, a determination of what constitutes an off balance sheet item (and what does not), will depend on professional judgement. The particular off balance items being referred to are consolidation and recognition standards. See FCAG Letter to G20 March 312009 <http://www.fasb.org/fcag/index.shtml>

$58 \quad$ ibid 
The FCAG primarily serves to advise the Boards (IASB and FASB) about "standard-setting implications of the global financial crisis" and "potential changes to the global regulatory environment." 59

A global approach is clearly required to tackle issues highlighted during the Financial Crises hence the IASB and FASB could be commended for their efforts. However, such efforts could yield unproductive results in the absence of effective enforcement mechanisms. The next section not only considers why accounting standards assume such a vital role in financial supervision, but also why given the absence of appropriate supervisory arrangements, the need for an effective enforcement standard setting mechanism becomes all the more important.

\section{The Role and Contribution of Accounting Standards in the 2007-2009 Financial Crisis}

The connection between prudential regulation and financial reporting is highlighted in the Final Report of the Financial Crisis Advisory Group. ${ }^{60}$ Whilst the Report states the purpose of the standard setter to be the promotion of "the reporting of unbiased, transparent and relevant information about the economic performance and condition of businesses, including financial institutions, to investors and other financial market participants", it also acknowledges that „both financial market participants and prudential regulators rely on financial reporting as an important basis for decision-making and both have a significant interest in market stability and economic growth.“61

The Report acknowledges the benefits from frequent exchanges between accounting standard setters and regulators in matters relating potential amendments to accounting standards attributing these to the facts that ,the interests of financial market participants and prudential regulators often overlap, and because prudential regulators are important users of financial reporting." 62 Furthermore, the FCAG acknowledges the contribution made by accounting standards in prudential regulation. ${ }^{63}$

\section{A. Accounting Standards' Contribution to Procyclicality}

The contribution of accounting rules and capital requirements in escalating the financial markets' problems, owing to their pro cyclical nature, has been highlighted. ${ }^{64}$ The pro cyclical nature of accounting is attributed to two principal elements, namely: ${ }^{65}$ fair value measurement and the treatment of impairments. The tendency of "volatility" (in financial statements) to

\footnotetext{
$59 \quad$ See FCAG Charter; ibid

60 See page 6 of The Final Report of the Financial Crisis Advisory Group July 2009

61 ibid

62 See ibid at 7

63 ibid

64 See 'International Financial Reporting Standards in Europe: McCreevy Seeks Loss Provisioning Reforms"< http://www.iasplus.com/restruct/euro2009.htm>

65 See M. Grande, 'Accounting and Procyclicality' Conference on Financial Reporting in a Changing World, at 2 of 5
} 
increase during periods of economic downturns, its resulting impact on pro cyclicality, its association with pro cyclical effects of capital requirements which could be triggered under Basel II and/or principles of risk management, have also been highlighted. ${ }^{66}$ Proposals aimed at countering the effects of pro cyclicality of fair value measurements include reclassifications, smoothing techniques and circuit breakers. ${ }^{67}$

The fourth recommendation of the High Level Group on Financial Supervision in the EU, which relates to accounting rules, considers "a wider reflection on the mark-to-market principle" to be vital. ${ }^{68}$ Furthermore, it is recommended that solutions should be found to resolve remaining accounting issues relating to complex products, that accounting standards should neither discriminate between business models, facilitate pro cyclical behaviour, nor deter long term investment. ${ }^{69}$

\section{B. The Contribution of Accounting Standards to the Improvement of Transparency and Accountability of the Framework for Fair Value Measurements and Evaluation (as reflected by the G20's recommendations to improve transparency and accountability).}

Recommendations aimed at consolidating transparency and accountability, as proposed by the G20, are to be achieved as a result of an improvement in the following areas: $:^{70}$

The improvement of standards which deal with the valuation of financial instruments based on their liquidity and investors' holding horizons, while affirming the framework of fair value accounting

- The introduction of measures aimed at simplifying accounting standards which deal with financial instruments

- Strengthening accounting recognition of loan- loss provisions through an incorporation of wider range of credit information

- The improvement of standards dealing with provisions, off-balance sheets exposures and uncertainties in valuation

\section{Will the above proposals be sufficient?}

1) Weaknesses in the current arrangements for macro prudential supervision

The weaknesses attributed to the existing arrangements for macro prudential supervision include: Insufficient focus on macro prudential aspects, fragmentation of macro prudential analysis - owing to the implementation of such an analysis by various authorities who not

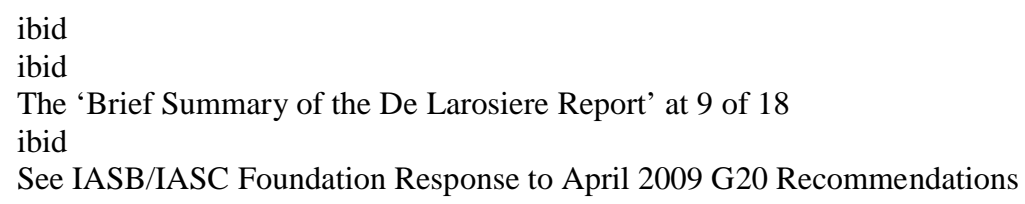


only operate at different levels, but also have no mechanisms in place to "follow-up and translate" macro prudential risk warnings and proposals into action. ${ }^{71}$

It is acknowledged that the European Union is in need of a distinct body which should not only assume responsibility for macro prudential supervision across the financial system in the EU, but should also be able to locate risks to financial stability, issue risk warnings and draft proposals which would address such warnings.$^{72}$ As part of efforts aimed at reforming macro supervision, the European Commission recommends the establishment of the European Systemic Risk Council (ESRC) as a "new independent body" which would be responsible for ensuring financial stability through its implementation of macro prudential supervision at European level. ${ }^{73}$ The new proposed supervisory framework will comprise of two pillars consisting of the European Systemic Risk Council and the European System of Financial Supervisors (ESFS) whose collaboration should achieve beneficial synergies. ${ }^{74}$

- 2) Initiatives undertaken by the Basel Committee for Banking Supervision

Recent Basel II initiatives include efforts aimed at introducing new standards to "promote the build up of capital buffers that can be drawn down in periods of stress, to strengthen the quality of bank capital, and to introduce a leverage ratio as a back stop to Basel II." ${ }^{, 75}$ Efforts being undertaken are also aimed at reducing excess cyclicality resulting from minimum capital requirements and facilitating "a more forward looking approach to provisioning."76

Efforts aimed at enhancing the three pillars of Basel II include the introduction of higher risk weights as means of reflecting (to a greater extent) the inherent risk in certain securitizations (Pillar 1), the consideration of particular areas such as firm wide governance and risk management, management and capture of risks, and the design of incentives aimed at helping banks to manage risks more appropriately (Pillar 2). ${ }^{77}$ The consolidation of securitisation exposures is also being considered (Pillar 3).

The first two recommendations of the High Level Group on Financial Supervision in the EU relate to the Basel Committee. ${ }^{78}$ In its first recommendation, the High Level Group proposed a "fundamental review of the Basel II rules" with the Basel Committee of Banking Supervisors being called upon to make amendments to such rules for the purpose of increasing minimum capital requirements in a gradual manner, reducing pro cyclicality through the facilitation of dynamic provisioning or capital buffers, introducing more stringent requirements for off balance sheet items, introducing stricter rules for the

\footnotetext{
71 See "Communication from the European Commission on European Financial Supervision" < http://ec.europa.eu/internal_market/insurance/docs/2009-markt-docs/communication-2009-252_en.pdf $>$ at 4 
management of liquidity, and consolidating rules for banks' internal control and risk management. ${ }^{79}$

The second recommendation proposes that a confirmation should be made by the Basel Committee in relation to " a common definition of regulatory capital in the EU" with clarification of which hybrid instruments are to be regarded as tier one capital. ${ }^{80}$

- 3) Consolidation of global arrangements by the G20 -aimed at ensuring financial stability at international level

To an extent, the successful accomplishment of the IASB's goals depends on efforts being undertaken (and the realised results) in the area of regulation and supervision. As part of the reinforcement of global arrangements by the G20, aimed at ensuring financial stability at international level, it has been agreed that "all systemically important financial institutions, markets and instruments should be subject to an appropriate degree of regulation and oversight." ${ }^{\prime 1}$ Such arrangements would require collaboration between the Financial Stability Board (FSB), BIS (Bank of International Settlements) and other international standard setters for purposes of developing tools which would be able to identify and account for macro prudential risks within the financial system. ${ }^{82}$ Furthermore, requirements aimed at monitoring funds' leverage and establishing limits for single counter party exposures, are to be imposed on institutions which have hedge funds as their counter parties - in order to ensure that effective measures of risk management are in place. ${ }^{83}$

- 4) IASB has no enforcement mechanism

The IASB has no enforcement mechanism. ${ }^{84}$ Whilst enforcement mechanisms exist in some member states of the EU, two of which will be considered later on in this paper, lack of enforcement mechanisms in other European member states, it is argued, could "diminish the effectiveness" of an EU capital market where enforcement takes place on a more rigorous level in some countries than in other EU countries. ${ }^{85}$ At present, enforcement actions are taken at national level - even though there is acknowledgement that a single EU securities market calls for "coordination and convergence of the enforcers' policies". ${ }^{86}$

\footnotetext{
$79 \quad$ ibid

ibid

See "Global Plan Annex - Declaration on Strengthening the Financial System"

<http://www.number10.gov.uk/Page18929>

82 ibid

83 ibid

$84 \quad$ See R. Lewis and D. Pendrill, Advanced Financial Accounting (Pearsons Education Ltd Seventh Edition 2004) at 53 and also B. Epstein and E. Jermakowicz, Interpretation and Application of International Financial Reporting Standards (John Wiley and Sons 2008) at 12

$85 \quad$ See R. Lewis and D. Pendrill, Advanced Financial Accounting (Pearsons Education Ltd Seventh Edition 2004) at 54

86 See CESR Standard No 1 (Enforcement of Standards on Financial Information in Europe) at 9
} 
A clarification and an agreement between the IASB and other accounting standard setters on a "common", "transparent" system for valuating illiquid market assets (where mark-to-market could not be applied) and the consolidation of the oversight and governance structure of the IASB, were amongst several points which were proposed by the High Level Group on Financial Supervision in its recommendations. ${ }^{87}$

Efforts aimed at strengthening three bodies responsible for the supervision of the securities, banking and insurance sectors, that is the CESR, CEBS and the CEIOPS were improved in February 2008, with the adoption European Commission, of measures which would facilitate a consolidation of the supervisory framework. ${ }^{88}$ Furthermore, this should also serve as a source of funding to European and international financial reporting standard setting bodies, including the IASB. ${ }^{89}$

Recommendations 16-24 of the High Level Group on Financial Supervision (Supervisory Repair) relate to the European Commission, the European Systemic Risk Council, the CEBS, CEIOPS, CESR and other supervisory bodies such as the IMF, FSF and BIS. ${ }^{90}$ The High Level Group on Financial Supervision not only recommended a collaboration between the Financial Stability Forum and international standard setters such as the Basel Committee for Banking Supervisors, but that such collaborative bodies be placed in charge of the facilitation of the convergence of international financial regulation for purposes aimed at attaining the highest standards. ${ }^{91}$

\section{Does the IASB's Principle Based Approach to Standard Setting Exacerbate Problems of Applying Auditing Standards More Consistently and Objectively?}

Even though the IASB's principle based approach to standard setting may contribute to the audit expectations gap ${ }^{92}$, judgement is considered to be important in the standard setting process. The need for some subjective element of judgement is demonstrated in the case of accounting accruals. Such subjective element contributes to managers and auditors' abilities to influence or manipulate accruals based results, depending on the incentives of such managers and auditors. ${ }^{93}$ The prescriptive application of rules is considered disadvantageous from the perspective where it adequately fails to take into account the substance of the transactions being undertaken. The coupling of rules with greater reliance on judgement has also been reiterated by the High Level Group on Financial Supervision in its recommendations. ${ }^{94}$

\footnotetext{
87 See the 'Brief Summary of the De Larosiere Report' at 9 of 18

88 See 'Strengthening CESR, CEBS and CEIOPS' and 'Funding IASB/IASCF, EFRAG, PIOB, and

CESR' http://www.iasplus.com/restruct/euro2009.htm

$89 \quad$ ibid

90 See pages 13-16 of the "Brief Summary of the De Larosiere Report" for Recommendations 16-24, for Recommendations 1-15 (Policy and Regulation Repair) see pages 8-12 .For Recommendations 25-31 (Global Repairs), see pages $17-18$

$91 \quad$ ibid at 17

92 The difference between what users of financial statements, the general public perceive an audit to be and what the audit profession claim is expected of them in conducting an audit.

93 See R. Ball, 'International Financial reporting Standards (IFRSs): Pros and Cons For Investors' 2006 Accounting and Business Research International Accounting Policy Forum at 17

$94 \quad$ See Report of the High Level Group on Financial Supervision, February 2009 <http://www.iasplus.com/restruct/euro2009.htm>and particularly, the 'Brief Summary of the De Larosiere Report' at page 8
} 
Reasons put forward to support a more principles based system of accounting include the fact that a more principles based approach is perceived to reduce complexity in the application of accounting and auditing standards. ${ }^{95}$ Furthermore, those who favour such an approach are unwilling to accept or permit a system of convergence which would result in a rule book approach to international standards. ${ }^{96}$

A rules based approach to accounting should lead to a more rigid and consistent application of standards than a principles based approach. However, it is contended that a principles based approach is not only easier to apply, but that it "actually generates more rigorous and consistent application of the standards' intent", that a principles based system would not necessarily imply that standards would be more relaxed, and that a well defined principle would facilitate "few exceptions" and clear boundaries - whose absence or limited presence had facilitated creative accounting practices. ${ }^{97}$ Difficulties in the implementation of rules are evidenced by the EC Regulation of 2002 and some other accounting directives. It is argued that accounting directives have achieved less harmonisation than was originally considered whilst constituting " an inflexible source of rules", which are "difficult to change in a business world which is constantly changing." 98

Furthermore it is acknowledged that the ability to maintain a principles based system would be dependent on companies, regulators, auditors, as well as standard setters. ${ }^{99}$

\section{Enforcement of Auditing Standards}

Enforcement can be defined as all procedures in a country in order to facilitate the proper application of accounting principles. ${ }^{100}$

\section{Standards Governing Enforcement in Europe}

Two related standards govern enforcement in Europe:

CESR Standard No1 (Enforcement of Standards on Financial Information in Europe)

CERS Standard No 2 (Coordination of Enforcement Activities)

The CESR Standard No.1 on Financial Information Enforcement of Standards on Financial Information in Europe is not only a principle based standard, but also provides for 'principles on which, in CESR's view, harmonization on the institutional oversight systems in Europe may be achieved. ${ }^{101}$

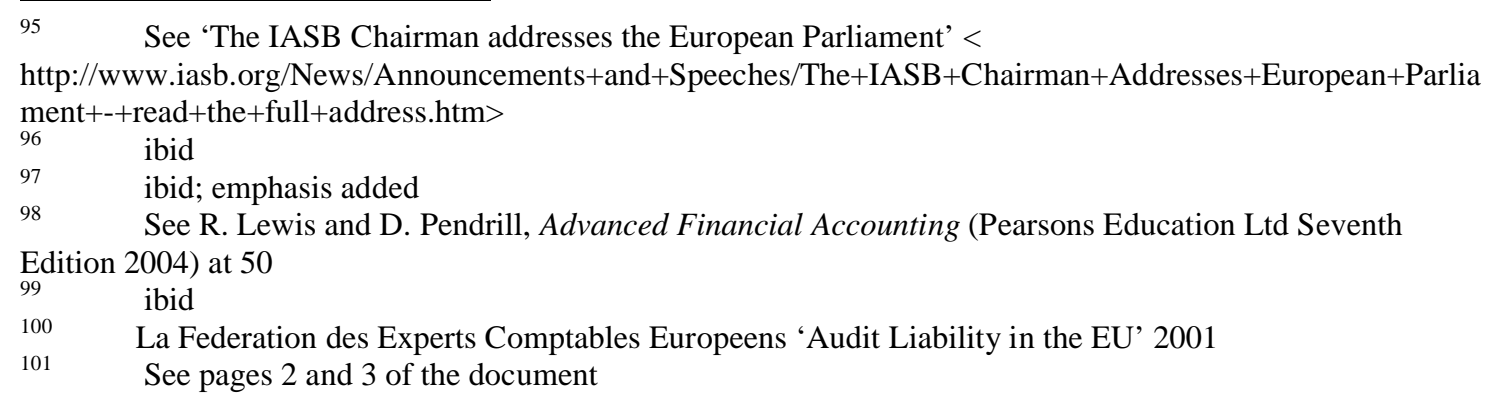


It particularly sets out 'a definition of enforcement of standards on financial information, its scope, the selection techniques applicable by the enforcers and the responsibility of the different parties involved are outlined. However, CESR recognises that enforcement of disclosure standards on prospectuses should take into consideration the special characteristics and definition of scope which will be defined by the evolving EU legislation'. ${ }^{102}$

Principle One and Two of "principles on which harmonisation of the institutional oversight systems in Europe may be achieved" 103 respectively stipulate the purpose ${ }^{104}$ and definition of enforcement.

According to Principle Two and for the purpose of the standard, the definition provided for enforcement is as follows : ${ }^{105}$..."monitoring compliance of the financial information with the applicable reporting framework ${ }^{106}$; taking appropriate measures in case of infringements discovered in the course of enforcement"

CESR's Standard No. 2 is also a principle-based standard which 'establishes a framework on the co-ordination of enforcement activities in relation to financial information throughout Europe', and which 'contains proposals for achieving the necessary co-ordination and convergence of enforcement activities carried out by EU National Enforcers'. ${ }^{107}$

\section{The Vital Role Assumed By Enforcement}

Recital No 16 : Regulation (EC) no 1606/2002 of the European Parliament and of the Council of 19 July 2002 on the application of international accounting standards states that:

"A proper and rigorous enforcement regime is key to underpinning investors' confidence in financial markets. Member States, by virtue of Article 10 of the Treaty, are required to take appropriate measures to ensure compliance with international accounting standards. The Commission intends to liaise with Member States, notably through the Committee of European Securities Regulators (CESR), to develop a common approach to enforcement."

\footnotetext{
<http://www.cmvm.pt/NR/rdonlyres/542657CE-77E4-47A2-BF28-

2A18F392C8C7/1559/norma1_inf_financeira.pdf>

$102 \quad$ ibid at page 4

103 See 'Standard No 1 on Financial Information Enforcement of Standards on Financial Information in

Europe" CESR, 2003 at 3

$104 \quad$ Principle 1states that: "The purpose of enforcement of standards on financial information provided by the issuers mentioned by principle 9 is to protect investors and promote market confidence by contributing to the transparency of financial information relevant to the investors' decision

making process. With regard to financial statements, the above implies that enforcement contributes to a consistent application of the IFRSs in the EU financial regulated markets."

See page 4 Standard No1 on Financial Information, Enforcement of Standards on Financial Information in Europe CESR, March 2003 < http://www.iasplus.com/europe/0303cesrstandard1.pdf>
}

105 See page 4 Standard No1 on Financial Information, Enforcement of Standards on Financial Information in Europe CESR, March 2003) < http://www.iasplus.com/europe/0303cesrstandard1.pdf>

$106 \quad$ "the reporting framework includes the accounting and disclosure standards adopted by the EU." see

ibid

See <http://www.cesr-eu.org/popup2.php?id=5788> 
Enforcement procedures are necessary in order to ensure that accounting and regulatory standards are being complied with. A good compliance culture can be defined as one which functions in accordance with the regulatory standards imposed on it. ${ }^{108}$ Enforcement can also be considered a constitution of several components such as clear accounting standards, prompt interpretation and implementation guidance, statutory audit, monitoring by supervisors and effective sanctions. ${ }^{109}$ It is argued that enforcement bodies should not only serve as information providers to other regulatory, supervisory or private oversight bodies, but should aim to impose sanctions where necessary. ${ }^{110}$ These functions, it is also contended, should be distinct from those related to standards setting, interpretation and the imposition of limits (relating to the application guidelines issued by the IASB and EFRAG). ${ }^{111}$ Characteristics which are considered to be vital for the effective functioning of enforcement bodies include: Support for high quality corporate governance and external audit, high quality expert decisions (on important issues) which are globally consistent, freedom from bias, transparency and clear procedures, confidentiality and speed of actions, the avoidance of detailed accounting rules, and sanctions. ${ }^{12}$ Furthermore, enforcement actions should be "effective, timely enacted and proportional to the impact of the detected infringement." 113

According to Ernstberger et $\mathrm{al}^{114}$, factors which ultimately define the level of compliance or accounting quality include the public enforcement of accounting standards, institutional arrangements within the firm, such as audit committees, and external parties such as auditors and securities regulators. Further, issues relating to managerial incentives and the institutional and legal framework, contribute to the level of enforcement. ${ }^{115}$ Based on their findings, they arrive at the conclusion that "so-called opportunistic earnings management motives and governance structures" contribute to the level of firms' compliance with mandatory reporting rules. ${ }^{116}$

Enforcement methods can be found under principles 11-15 of CESR Standard No1. ${ }^{117}$ According to principle 13, even though an approach based solely on risk may be an acceptable selection method, the preferred models for selecting financial information for enforcement purposes are combined models in which a risk based approach is coupled with a rotation and/or a sampling approach. ${ }^{118}$

\footnotetext{
108 R. Turner, The Interaction between FSA Enforcement Action and Compliance: A Help or a Hindrance? (2005) 13 (2) Journal of Financial Regulation and Compliance (Henry Stewart Publications 142

109 Federation des Experts Comptables Europeens ,Enforcement Mechanisms in Europe: A Preliminary Investigation of Oversight Systems' April 2001 at 4

110 A. Dutescu, 'Harmonization of International Accounting Standards in Europe' 2003 at 3

111 ibid; Furthermore Principle 17 of CESR Standard No 1 states that "Actions taken by enforcers should

be distinguished from sanctions imposed by the national legislation."

112 ibid

113 See Principle 18 of CESR Standard No 1

114 See J. Ernstberger, J. Hitz and M. Stich 'Enforcement of Accounting Standards in Europe: Empirical

Evidence for the Two-Tier Mechanism in Germany' 2009 at14

115 ibid

116 ibid at 42

117 Enforcement of Standards on Financial Information in Europe at 7

118 See ibid
} 
The enforcement of audit standards appears in most European countries at 6 levels namely: ${ }^{119}$

- Preparation of financial statements

- Statutory audit of financial statements

- Approval of financial statements

- Institutional oversight systems

- Court

- Public and press reactions

The enforcement mechanisms and the level of enforcement undertaken in different member states differ to an extent as will be illustrated in the subsequent section. It has been discovered that "the level of convergence of accounting practice depends on regulatory enforcement and capital market incentives." 120

\section{Enforcement Systems in Germany and the UK}

Enforcement System in Germany

The two tier enforcement system in Germany which was established in 2004, comprises of a private body, the Deutsche Prïfstelle für Rechnungslegeung (DPR), which is responsible for the investigation of matters related to compliance with financial statements published by publicly traded firms, and BaFin (Federal Financial Supervisory Authority) - which "enforces" the disclosure of the DPR at a second level. ${ }^{121}$ Based on results which concerned "significant investor reactions to the DPR's (German Financial Reporting Panel) error findings", Ernstberger et al contend that a deduction can be made in relation to the effectiveness of the German enforcement system, and, accordingly, conclude that the enforcement system which operates in Germany is effective in its efforts to penalise enterprises which have violated rules and that this consequently bolsters the "deterrence effect" which also generates a positive influence in inducing firms listed in Germany to comply with accounting rules. ${ }^{122}$

In Germany, proactive examinations which are based on sampling are instigated in accordance with requests of the "Sampling Committee", based on principles which can be found in Section 342b (2) HGB which states that "Sampling shall be conducted in accordance with principles to be defined by the enforcement panel in consultation with the Federal Ministry of Finance. The Federal Ministry of Finance may transfer the authority to issue its approval to the Federal Financial Supervisory Authority.",123

\section{Enforcement System in the UK}

\footnotetext{
119 Federation des Experts Comptables Europeens, Enforcement Mechanisms in Europe: A Preliminary Investigation of Oversight Systems' April 2001 at 8

See S. Cascino and J. Gassen, 'Do Harmonized Accounting Standards lead to Harmonized Accounting? German Italian Evidence' 2009 at 11 and also MT. Bradshaw and GS. Miller, 'Will Harmonizing Accounting Standards Really Harmonize Accounting?' Evidence from Non US Firms adopting US GAAP, 2007 Working Paper

121 See J. Ernstberger, J. Hitz and M. Stich 'Enforcement of Accounting Standards in Europe: Empirical Evidence for the Two-Tier Mechanism in Germany' 2009 at 2

122 ibid at 42

123 See J. Ernstberger, J. Hitz and M. Stich 'Enforcement of Accounting Standards in Europe: Empirical Evidence for the Two-Tier Mechanism in Germany' 2009 at 12
} 
The body responsible for the enforcement of accounting standards in the UK, the Financial Reporting and Review Panel (FRRP), not only functions to examine apparent departures from the accounting requirements of the 1985 Companies Act, including applicable accounting standards, but also to seek an order from the court to remedy them - if necessary. ${ }^{124}$ Following the collapse of Enron, reforms were put in place by the government and these included assigning to the FRRP the task of proactively investigating listed company accounts for inaccuracies rather than waiting for a complaint to be made. ${ }^{125}$ Bittlestone disagrees with the views shared by Fearnley and Hines ${ }^{126}$ that proactive investigation would be costly for little benefit. Furthermore, he not only argues that technology could be adopted by the FRRP at a fraction of the costs feared by Fearnley and Hines, but that a proactive FRRP would also assist in restoring investor faith in the level of quality of financial reporting in the aftermath of such failures like Enron. ${ }^{127}$ One of the products which resulted from the review of the regulatory regime for accounting and auditing in the UK, consisted of a combined approach ( a risk based approach to the enforcement of accounting requirements in addition to the previously existing reactive, complaints-driven approach). ${ }^{128}$

\section{Proactive Examinations rather than Complaints Driven Approaches?}

Proactive examination should be encouraged bearing in mind the goal of minimising costs whenever possible.

\section{According to CESR Standard No1: ${ }^{129}$}

"Cost-benefit and risk considerations, along with other factors like the availability of information, indications by the auditors and apparent inconsistencies of the enforced document should be taken into account when determining the intensity of review."

Furthermore, investigations relating to enforcement actions should be undertaken subject to an initial scrutiny and where complaints which have been received appear to be "reliable and relevant" for an instigation of enforcement action. ${ }^{130}$

Contribution of external auditors in facilitating greater level of pro active monitoring at EU Level. ${ }^{131}$

\footnotetext{
124 R. Bittlestone, 'Now For the Quake Test' Financial Times November 2003

125 ibid

126 See S. Fearnley and T. Hines, 'Sour Taste of Bad Law' September 252003

$127 \quad$ ibid at 2

128 See http://www.frc.org.uk/about/annual.cfm at pages 12 and 13

129 See Enforcement of Standards on Financial Information in Europe at page 8 <http://www.iasplus.com/europe/0303cesrstandard1.pdf>

130 ibid
} 
EFRAG's roles are pro active as well as reactive. ${ }^{132}$ These roles particularly include:

- the provision of advice to the European Commission on the endorsement of new or amended IFRSs and IFRIC interpretations

- the provision of comments on proposed IFRSs and IFRIC interpretations, IASB discussion papers and other consultative documents

- Attendance of various IASB working group meetings as observers

- The retention of close contacts with the IASB through meetings with its chairman

- Close collaboration with European national standard setters and world standard setters

Given the weaknesses in macro prudential supervision and the contribution of audit standards in facilitating financial stability (as revealed by the recent financial crisis), close collaboration with European national standard setters, as well as global standard setters, as well as other above mentioned roles would assist in mitigating weaknesses in macro prudential supervision arrangements.

\section{Conclusion}

The enforcement of audit standards at European level, is an area which needs to be addressed. Based on the results of the peer review carried out by the CESR's peer pressure group, the Review Panel, in July 2009: ${ }^{133}$

- Less than half ( $45 \%$ ) of CESR's members were discovered to be fully applying standard No 2 in day to day enforcement activities

- Just less than a third of CESR members were discovered to be fully applying the Standard. Further, a considerable number of CESR members accounting for more than $50 \%$, did not apply the principles in its entirety.

Even though it is contended that "a harmonization of enforcement mechanisms in Europe is needed in order to contribute to the creation of an efficient single capital market in Europe within the context of the evolving EU legislation", convergence is considered to be an arduous, if not unfeasible objective. ${ }^{134}$ The enforcement of accounting and auditing standards at European level is a necessity given the fact that no such mechanism currently operates. In view of the vital role which convergence assumes in the standard setting process, the FEE has called for a re think of the way in which convergence is implemented - if such a goal is to be realised: ${ }^{135}$

131 For greater in depth analysis on how external auditor's expertise could be harnessed more effectively in pro active monitoring processes undertaken by regulators and standard setters, please refer to M. Ojo, 'The Need For Greater Pro Active Involvement By Regulators In Financial Regulation and Supervision: Lessons From the Legal and General Case'

132 See ,European Financial Reporting Advisory Group' < http://www.efrag.org/content/default.asp?id=4103>

133 See 'Summary of CESR's Self Assessment of the Implementation of Standard No 2 on Financial Information - Coordination of Enforcement Activities' and 'Final Report on CESR's Peer Review of the Implemenatation of Standard No 2 on Financial Information) http://www.cesr-eu.org/data/document/09_188.pdf

$134 \quad$ R. Ball, 'International Financial reporting Standards (IFRSs): Pros and Cons For Investors' 2006 Accounting and Business Research International Accounting Policy Forum at 6 and 17

135 FEE's statement 'A New Approach To Setting Global Financial Reporting Standards' see < http://www.iasplus.com/europe/0907feepolicy.pdf $>$ (page 2 of 2) 
"The concept of convergence and the role it plays in the IASB's priority setting needs to be reconsidered. FEE believes that the existing model of convergence is no longer sustainable due to diminishing returns and therefore 'calls for a new approach that is based on working together towards developing the highest quality principles based financial reporting solutions in duly identified key priority areas. The development of new financial reporting standards should go beyond the thinking under existing national standards. A joint development and parallel implementation by all stakeholders of new global principles-based standards is the best way forward to develop high quality standards and to deliver a level playing field, without favouring input from one jurisdiction over another. The IASB would then truly be operating as an international body.”

In view of perceived diminishing returns from continued convergence arising from increased complexity, and the relatively low benefits emerging in attempting to mitigate smaller variations between IFRS and other standards, the FEE is of the opinion that convergence should not longer constitute the principal driver in the financial reporting debate. ${ }^{136}$ The FEE proposes a change to the IASB's strategy and recommends a medium term focus on substantial improvements and reduced complexity in IFRSs. ${ }^{137}$ Further, as a means of achieving such improvement, it recommends collaboration with other international standard setting bodies, reduction in the number of active projects being undertaken in order to pave the way for the development of future standards. ${ }^{138}$ The FEE considers a "single independent global standard setter for accounting and corporate reporting" to be the best means of facilitating markets in which high quality financial information is transmitted between countries. $^{139}$

In accordance with Regulation (EC) no $1606 / 2002,{ }^{140}$ CESR should have a role in the development of standards for enforcement. ${ }^{141}$ In particular, consideration should be given to Principle 5 of the principles on which harmonisation on the institutional oversight systems in Europe may be achieved, which states that "Irrespective of who carries out enforcement, any standard on enforcement established by the CESR should be complied with". ${ }^{142}$

Furthermore, "active participation" by preparers and users of financial statements ${ }^{143}$, at an international level, is considered vital to securing general acceptability of resulting standards, which accordingly, should promote the adoption ${ }^{144}$ of IFRS in major countries.$^{145}$

Having considered the benefits and disadvantages of a rules based and principals based approach to standard setting and in view of difficulties which arise in implementing a rules based approach, a principles based system to standard setting which, to a greater extent, would respond, evolve and adapt to the changes of a constantly changing global environment, appears to be well justified. In the absence of enforcement mechanisms however, there are even greater limits to what such principles based approach to regulation could achieve. The need for a body such as the IASB to have an enforcement mechanism is further exacerbated by the Basel Committee (for Banking Supervision)'s lack of effective enforcement

\footnotetext{
136 See FEE's Policy Statement 'Future Approach to Setting Global Financial Reporting Standards' page 1 of 2, http://www.iasplus.com/europe/0907feepolicy.pdf (last visited 7 September 2009)

137 ibid

138 ibid

139 ibid

140 Of the European Parliament and of the Council of 19 July 2002 on the application of international accounting standards - see recital No 16 of the Regulation

141 Also see Standard No 1 (Enforcement of Standards on Financial Information in Europe) at 3

142 For information on all the principles, see Standard No 1 (Enforcement of Standards on Financial Information in Europe)

$143 \quad$ Also see Presentation by H van Damme, FEE President, EC Conference: 'Financial Reporting in a Changing World, How to Keep Financial Reporting Relevant'.

144 A full adoption of such IFRSs is recommended; see "Need for Global and Principle based standards" $<$ http://ec.europa.eu/internal_market/accounting/docs/conference_052009/van_damme_en.pdf >
} 
mechanisms. The High Level Group's recommendations to the Basel Committee, a body with weak enforcement mechanisms is therefore considered to be a futile exercise. 
